\title{
Effects of nicotine on the human nasal mucosa
}

\author{
L Greiff, P Wollmer, I Erjefält, M Andersson, U Pipkorn`, C G A Persson
}

\begin{abstract}
Background-Topical application of nicotine and stimulation of tachykinin containing sensory nerves have been shown to produce mucosal exudation of plasma and derangement of the epithelial lining in guinea pig and rat airways. If this occurred in man these effects might contribute to the pathogenesis of airway disease. This study, performed in healthy volunteers without atopy, examined whether nicotine affects the plasma exudation response and the mucosal absorption permeability of the human nasal airway.
\end{abstract}

Methods-The acute effects of increasing topical doses of nicotine $(0 \cdot 08-2 \cdot 0 \mathrm{mg})$ were examined $(n=8)$ on nasal symptoms (pain), mucosal exudation of plasma (albumin), mucosal secretion of mucin (fucose), and mucosal exudative responsiveness (histamine induced mucosal exudation of albumin). A separate placebo controlled study was carried out to determine whether frequent applications of the high dose of nicotine (2.0 mg given eight times daily for nine days) had any deleterious effects on the airway mucosa detectable as altered responses to histamine challenge. Both mucosal exudation of plasma $(n=12)$ and mucosal absorption of chromium-51 labelled EDTA $(n=8)$ were thus examined in nasal airways exposed to both nicotine and histamine.

Results-Nicotine caused nasal pain and produced dose dependent mucosal secretion of fucose but failed to produce any mucosal exudation of albumin. The exudative responsiveness to histamine was, indeed, decreased when the challenge was performed immediately after administration of acute doses of nicotine, whereas the responsiveness was unaffected when histamine challenges were carried out during prolonged treatment with nicotine. The nasal mucosal absorption of ${ }^{51} \mathrm{Cr}$-EDTA in the presence of histamine did not differ between subjects receiving either placebo or nicotine treatment for nine days.

Conclusions-The results indicate that nicotine applied to the human airway mucosa produces pain and secretion of mucin, but inflammatory changes such as mucosal exudation of plasma and epithelial disruption may not be pro- duced. Neurogenic inflammatory responses, which are so readily produced in guinea pig and rat airways, may not occur in human airways.

(Thorax 1993;48:651-655)

The smoking of tobacco may make nicotine the most widely used inhaled drug. Nicotine is a ganglionic stimulant drug. Like capsaicin it also stimulates airway sensory innervation to produce secretion, bronchoconstriction, and cough in man. ${ }^{1-3}$ In guinea pig tracheobronchial airways we have shown that nicotine, ${ }^{4}$ like capsaicin, ${ }^{5}$ produces mucosal exudation of plasma. This effect is induced by stimulation of lignocaine sensitive nerves, probably of the tachykinin containing type. ${ }^{45}$ Plasma exudation is of potential importance in the pathogenesis of airway diseases. ${ }^{6}$ Other potentially harmful effects induced by stimulation of the airway tachykinin innervation have been shown in rats by $\mathrm{McD}$ onald, ${ }^{7}$ who observed severe derangement of the epithelial lining. Tachykinin containing nerves are present in human upper and lower airways. ${ }^{8}$ The effects of nicotine on mucosal exudation of plasma and on epithelial barrier function of human airways are unknown, but they may constitute a significant function of the pharmacology of this agent.

We have used novel nasal challenge and lavage procedures to examine the effects of nicotine on human airway mucosa. We first examined the acute effects of increasing doses of nicotine on nasal symptoms (pain), mucosal exudation of plasma (albumin), mucosal secretion of mucin (fucose), and mucosal exudative responsiveness (histamine induced mucosal exudation of albumin). We then assessed whether frequent applications of a high dose of nicotine for several days produced any deleterious effects on the airway mucosa, as could be detected by altered responses to inflammatory mediator challenge. Both mucosal exudation of plasma and mucosal absorption permeability were examined in human nasal airways exposed to nicotine and histamine.

\section{Methods}

ACUTE EFFECTS OF INCREASING DOSES OF NICOTINE ON THE NASAL MUCOSA Subjects

Eight non-smokers aged 23-41 (mean 29) 
years participated in the study. The subjects had no history of atopic or ongoing airway disease. No drugs were allowed during the course of the study. The study was approved by the ethics committee at Lund University Hospital and informed consent was obtained from the subjects. Blinding of this part of the study was not attempted because of clearcut nicotine induced nasal sensations (pain).

Nasal pool technique

The nasal pool technique was used for histamine challenge, saline lavage, and tracer instillation. This device is a compressible plastic container equipped with a nasal adapter. The nasal adapter is inserted into one of the nostrils and the container is compressed by the subject sitting at a $60^{\circ}$ forward flexed neck position. The nasal pool fluid is then instilled and maintained in the unilateral nasal cavity as the anterior nasal opening is occluded by the nasal adapter. When the pressure on the nasal pool device is released the fluid returns into the container. This technique gently and effectively irrigates a large area of the nasal mucosal surface. The total volume of the nasal pool fluid was 14 $\mathrm{ml}$, and $8-10 \mathrm{ml}$ was instilled to fill the unilateral nasal cavity.

\section{Nasal administration of nicotine and measurement of histamine induced mucosal exudation of plasma (albumin)}

A pump spray delivering $100 \mu \mathrm{l}$ per actuation was used for nasal administration of control saline and nicotine solutions. A series of four control saline administrations was performed first, and a series of four nicotine challenges four hours later. Control saline administrations and each dose of nicotine $(0,0.08,0.4$, and $2.0 \mathrm{mg}$ ) were administered as single actuations at 20 minute intervals. During a period of two minutes before each administration the mucosal surface was lavaged twice for 30 seconds with saline by the nasal pool technique. These lavages were performed to create a low and consistent baseline of albumin and fucose, and the fluids were not collected. Ten minutes after each administration of saline or nicotine the mucosal surface was lavaged by keeping the nasal cavity filled with saline for five minutes using the nasal pool technique. These lavage fluids were collected. Immediately after the last five minute saline lavage the mucosal surface was challenged with a histamine solution $(0.4 \mathrm{mg} / \mathrm{ml})$ maintained in the nasal cavity for 10 minutes by the nasal pool technique. This combined challenge and lavage fluid was also collected. The nasal lavage fluid samples were analysed for albumin as an index of mucosal exudation of plasma and for fucose as an index of mucosal secretion of mucin.

\section{Chemical assays}

Lavage fluid albumin concentrations were analysed with a radioimmunoassay sensitive to $6.25 \mathrm{ng} / \mathrm{ml}$. The anti-albumin was purchased from Dakopatts (Copenhagen, Denmark) and the standard substance from
Calbiochem (San Diego, California, USA). Iodination was performed with the lactoperoxidase method to a specific activity of 2.0 $\mathrm{mCi} / \mathrm{nmol}$. The intra-assay and interassay coefficients of variation were less than $5 \%$ and $10 \%$, respectively. Lavage fluid fucose concentrations were analysed as described by Cohenford et al. ${ }^{10}$ The interassay coefficient of variation was less than $6 \%$.

EFFECTS OF FREQUENT APPLICATIONS OF A HIGH DOSE OF NICOTINE ON THE NASAL MUCOSA

Subjects

Twelve men aged 22-28 (mean 24) years participated in the study. The subjects had a history of daily nicotine use (oral snuff or cigarettes) but no history of atopic or airway disease. No drugs were allowed during the course of the study. This part was designed as a single blind, placebo controlled, crossover study. The subjects were provided with an allocation number and the order of treatment proceeded according to a randomisation scheme prepared in blocks. Blindness was maintained by the identical appearance of active and placebo drug delivering devices and by an attempt to achieve identical smells of active and control solutions. (Nicotine induced sensations exhibited tachyphylaxis and therefore blindness was not entirely destroyed.) Compliance was ascertained by interview with each subject of this small panel of subjects who have participated in several previous studies.

\section{Nasal administration of nicotine and measurement of histamine induced mucosal exudation of plasma (albumin)}

A pump spray delivering $100 \mu \mathrm{l}$ per actuation was used for nasal administration of placebo and nicotine solutions. Placebo or nicotine $(2.0 \mathrm{mg})$ was administered as a single actuation eight times daily (once every two hours during daytime) for nine days. Immediately before the start of the administrations, and subsequently every second day, histamine challenges were carried out (between 1600 and 1800 hours and at least 30 minutes after administration of nicotine) as described above. A 10 minute challenge with histamine $(0.4 \mathrm{mg} / \mathrm{ml})$ using the nasal pool device was given and the nasal pool fluids collected and the albumin concentrations measured as an index of mucosal exudation of plasma. During a period of two minutes before histamine administration the mucosal surface was lavaged twice for 30 seconds with saline by the nasal pool technique. These lavages were performed to wash away any accumulation of albumin on the mucosal surface and the fluids were not collected. The concentration of histamine was selected from the results of preliminary experiments indicating that only mild and transient symptoms occurred (not scored in the present study).

Nasal absorption of ${ }^{51} \mathrm{Cr}$-EDTA ${ }^{11}$

Absorption of ${ }^{51} \mathrm{Cr}$-EDTA (MW 372) across the nasal mucosa in the presence of histamine 
Table 1 Acute effects of increasing doses of topical nicotine (0-2.0 mg) on mean (SE) mucosal exudation of plasma (albumin) and secretion of mucin (fucose).

\begin{tabular}{lllll}
\hline & Nicotine $(\mathrm{mg})$ & Lavage (no) & Albumin $(\mu \mathrm{g} / \mathrm{ml})$ & Fucose $(\mu \mathrm{g} / \mathrm{ml})$ \\
\hline Saline (control) & - & 1 & $1 \cdot 5(0 \cdot 6)$ & $4 \cdot 1(2 \cdot 3)$ \\
& - & 2 & $2 \cdot 1(0 \cdot 9)$ & $4 \cdot 4(1 \cdot 7)$ \\
& - & 3 & $1 \cdot 3(0 \cdot 4)$ & $4 \cdot 9(1 \cdot 5)$ \\
Nicotine (challenge) & 0 & 4 & $1 \cdot 8(0 \cdot 6)$ & $5 \cdot 6(1 \cdot 5)$ \\
& $0 \cdot 08$ & 1 & $4 \cdot 8(2 \cdot 4)$ & $2 \cdot 5(0 \cdot 4)$ \\
& $0 \cdot 4$ & 3 & $2 \cdot 9(1 \cdot 0)$ & $6 \cdot 4(1 \cdot 1)$ \\
& $2 \cdot 0$ & 4 & $3.5(1 \cdot 2)$ & $18(5 \cdot 5)$ \\
& & & $2 \cdot 9(0.9)$ & $20(9 \cdot 7)^{\star}$ \\
\hline
\end{tabular}

${ }^{\star} \mathrm{p}<0.05$.
Results

Nicotine $(0.08-2.0 \mathrm{mg})$ administered onto the human nasal mucosa failed to produce mucosal exudation of albumin $(p>0.05)$ but produced dose dependent mucosal secretion of fucose $(\mathrm{p}<0.05)$ (table 1 ). Administration of nicotine $(2.0 \mathrm{mg})$ was associated with an intense nasal pain in all subjects, and four subjects also reported moderate nausea. Histamine produced significant mucosal exudation of albumin when the challenge was given immediately after either saline or nicotine $(p<0.001)$ compared with the baseline albumin value obtained after the first saline administration. The histamine induced exudation of albumin was, however, less after the acute nicotine challenges (94 (30) $\mu \mathrm{g} / \mathrm{ml})$ than after saline (200 (52) $\mu \mathrm{g} / \mathrm{ml})$ $(\mathrm{p}<0.01)$.

Nicotine $(2.0 \mathrm{mg})$ administered onto the human nasal mucosa eight times daily for nine days did not affect the exudative responsiveness to histamine as measured by mucosal exudation of albumin ( $p>0.05$; ANOVA) (table 2). The subjects receiving nicotine reported an initial nasal pain that was brief and decreased during the first day of repeated administrations. Further administrations of nicotine were associated with a mild nasal irritation but no nasal pain.

The airway absorption of ${ }^{51} \mathrm{Cr}$-EDTA in the presence of histamine was unaffected by the treatment with nicotine $(2.0 \mathrm{mg}$ eight times daily for nine days). The mean (SE) absorbed volume of the nasal instillate was $0.6(0.2) \mathrm{ml}$ after the placebo treatment and $0.4(0.2) \mathrm{ml}$ after the nicotine treatment ( $p>0.05)$. (each $3.0 \mathrm{ml}$ ) of the standard solution, prepared by diluting $0 \cdot 1 \mathrm{ml}$ of the nasal instillate to $100 \mathrm{ml}$, were counted together with the urine samples. The amount of ${ }^{51} \mathrm{Cr}$-EDTA absorbed was expressed as the corresponding volume of the nasal instillate.

\section{STATISTICS}

Data are presented as mean (SE). Analyses of variance (ANOVA) were performed to examine differences in obtained measurements. Wilcoxon's signed rank test was used for further analyses of albumin and fucose concentrations respectively and $p$ values less than 0.05 were considered significant.

Table 2 Effects of frequent nasal applications of nicotine $(2.0 \mathrm{mg})$ administered eight times daily for nine days on mean (SE) mucosal exudation of plasma (albumin) induced by repeated challenges to histamine $(0.4 \mathrm{mg} / \mathrm{ml})$.

\begin{tabular}{lll}
\hline & $\begin{array}{l}\text { Histamine challenge } \\
\text { day }(\text { no })\end{array}$ & Albumin $(\mu \mathrm{g} / \mathrm{ml})$ \\
\hline Placebo & 1 & $231(42 \cdot 8)$ \\
treatment & 3 & $326(110)$ \\
& 5 & $215(59 \cdot 8)$ \\
& 7 & $168(40 \cdot 6)$ \\
Nicotine & 9 & $223(47 \cdot 7)$ \\
treatment & 1 & $350(131)$ \\
& 5 & $159(41 \cdot 9)$ \\
& 7 & $152(47 \cdot 9)$ \\
& 9 & $227(123)$ \\
\hline
\end{tabular}

\section{Discussion}

The results of this study show that nicotine does not produce mucosal exudation of plasma in human nasal airways, nor does it increase the exudative responsiveness of the airway mucosa or increase the mucosal absorption permeability. Nicotine may not therefore produce those potentially harmful effects that are induced by stimulation of the tachykinin nerves of rodent airways. ${ }^{4}$

The inflammatory responses of the human nasal mucosa can give an insight into responses in the tracheobronchial mucosa. ${ }^{6}$ Allergen, histamine, bradykinin, and leukotriene $\mathrm{D}_{4}$, in contrast to nicotine (and capsaicin), are thus potent inducers of airway exudation irrespective of species and irrespective of nasal or tracheobronchial airways, ${ }^{12-14}$ (and unpublished observations by $M$ Andersson, L Greiff, C Svensson, U Alkner, CGA Persson). In contrast to our previous findings in guinea pig tracheobronchial airways ${ }^{4}$ nicotine failed to produce mucosal exudation of plasma in this human nasal airway study. Although nicotine was given at high doses that produced pain as well as dose dependent mucosal secretion of fucose, no exudative effect could be recorded, nor did nicotine induce any acute increase in the mucosal exudative responsiveness as mea- 
sured by the response to a histamine challenge. Furthermore, several days of intense exposure of the human airway mucosa to this neural stimulant did not increase the exudative responsiveness to histamine. The difference between the effect of nicotine on human nasal and guinea pig tracheobronchial airways may reflect a true species difference rather than a regional airway difference.

The mucosal exudation of plasma is largely a non-sieved process and, as well as albumin, the very large plasma proteins such as fibrinogen and $a_{2}$ macroglobulin are exuded. The non-sieved nature is independent of whether the stimulus is a mediator, allergen, or whether the challenge is given to the nasal or to the bronchial mucosa. ${ }^{12}$ Furthermore, mucosal exudation of non-sieved plasma is seen in normal airways with intact epithelial linings. ${ }^{616} \mathrm{~A}$ series of in vitro and in vivo studies suggest that the luminal entry of plasma is regulated by small increases in the subepithelial hydrostatic pressure that transiently separates the epithelial cell junctions so that a unidirectional, paracellular flux of solutes moves into the airway lumen. ${ }^{17} 18$ The apparent ease with which luminal entry of plasma occurs, even at threshold exudative stimuli, is consistent with our inability to detect airway oedema formation and increased lymphatic transport of plasma proteins in airways challenged with exudative agents. ${ }^{19} 20$ The obligatory luminal entry of extravasated plasma is an important consideration in the present study where only surface liquids were sampled. Nicotine may not have caused extravasation of plasma into the lamina propria without an increase of albumin (or other plasma proteins) occurring in the airway lumen. The mechanism of epithelial passage of extravasated plasma thus strengthens the present conclusion that nicotine does not produce plasma exudation in human airways.

The lack of a neurogenic mucosal exudative response in human nasal airways is consistent with preliminary findings that capsaicin has no exudative effects in human nasal airways ${ }^{21}$ (and unpublished observations by $M$ Andersson, L Greiff, $C$ Svensson, U Alkner, CGA Persson). Malm and Petersson, ${ }^{22}$ Karlsson et al, ${ }^{23}$ Miadonna et al, ${ }^{24}$ and Gepetti et al ${ }^{25}$ found no rhinorrhea inducing effects of substance $P$ administered onto the human nasal mucosal surface. Since large doses of substance $P$, which produce systemic circulatory effects, have been administered in these studies, the lack of mucosal effect is perhaps not explained by rapid metabolic breakdown of this tachykinin. ${ }^{26}$ As indicated by the increased amounts of fucose, a component of mucin, ${ }^{10}$ nicotine stimulated airway mucosal secretion in this study. Fucose is a relatively specific marker of macromolecular mucins $^{10}$ and its concentration in plasma is much less than that of other secretory indices such as sialic acid. ${ }^{27}$ Since there was no increase at all in luminal albumin it seems clear that mucin secretion can occur without concomitant secretion of albumin. Indeed, the secretion of albumin, in contrast to its exudation, may only be marginal in human airways. Raphael et al thus observed that even a large dose of methacholine $(25 \mathrm{mg})$ produced only a two fold increase in luminal albumin $^{28}$ whereas in this study histamine increased albumin levels 100 fold or more. The mechanisms involved in the nicotine induced secretion have not been determined. It is possible that the nicotine induced secretion may have contributed to the reduced plasma exudation response when histamine was administered immediately after the highest nicotine dose by binding or otherwise preventing the access of histamine to the subepithelial target.

Nasal administration of nicotine may find practical use as an adjunct in smoking cessation programmes. ${ }^{29}$ The present study showed that nasal administration of a substantial dose of nicotine, $2.0 \mathrm{mg}$ eight times daily for nine days, was well tolerated. To avoid repeated exposures to radioactivity we examined the absorption of ${ }^{51} \mathrm{Cr}$-EDTA only after treatment with both nicotine and histamine. It seems likely, however, that nicotine alone could not have disrupted the epithelial lining and increased the paracellular absorption of the hydrophilic ${ }^{51} \mathrm{Cr}$-EDTA. The absorption rate of ${ }^{51} \mathrm{Cr}$-EDTA in this study was similar to that observed previously in healthy volunteers challenged with either saline or histamine. ${ }^{11}$

We conclude that airway mucosal challenge with nicotine produces a range of responses characteristic of a strong irritant, although repeated administration causes tachyphylaxis to pain. However, inflammation and epithelial disruption may not be produced by nicotine in human airways. The present observations, while suggesting the possibility of employing nicotine inhalations without harmful sequelae, cast some doubt on the relevance to man of the neurogenic inflammatory responses which are so readily produced in guinea pig and rat airways.

We thank Ulf Alkner for carrying out albumin analyses and Tobias Danielsson for carrying out fucose analyses.

This study was supported by grants from the Swedish Medical Research Council (projects 8308 and 2872), the Medical Faculty of Lund University, the Swedish Association against Asthma and Allergy, and the Torsten and Ragnar Söderberg Foundation.

1 Stjärne P, Lundblad L, Lundberg JM, Änggård A Capsaicin and nicotine-sensitive afferent neurones and nasal secretion in healthy human volunteers and in patients with vasomotor rhinitis. Br F Pharmacol 1989; 96:693-701.

2 Hansson L, Karlsson JA, Choudry N, Fuller R. Human airway reflexes: effects of inhaled nicotine. Thorax 1988; 43:836 (abstract)

3 Midgren B, Hansson L, Karlsson J-A, Simonsson BG, Persson CGA. Capsaicin-induced cough in man. $A m$ Rev Respir Dis 1992;146:347-51.

4 Greiff L, Erjefält I, Wollmer P, Andersson M, Pipkorn U, Alkner $U$, et al. Nicotine evokes neurogenic mucosal exudation of plasma into guinea pig but not into human airways. In: Greiff L. Plasma exudation and solute absorpairways. In: Greiff L. Plasma exudation and solute absorption across the airway mucc
University, 1991:109-23.

5 Persson CGA, Erjefält I. Inflammatory leakage of macromolecules from the vascular compartment into the tra- 
cheal lumen. Acta Physiol Scand 1986;126:615-6.

6 Persson CGA, Svensson C, Greiff L, Andersson M Wollmer P, Alkner U, et al. The use of the nose to study the inflammatory response in the respiratory tract (editorial). Thorax 1992;47:993-1000.

$7 \mathrm{McD}$ onald DM. Neurogenic inflammation in the trachea I. Changes in venules, leukocytes, and epithelial cells. $f$ Neurocytol 1988;17:583-603.

8 Sundler F, Uddman R. Neuropeptides in the airways: a review. Am Rev Respir Dis 1987;136:S3-8.

9 Greiff L, Alkner U, Pipkorn U, Persson CGA. The "nasal pool-device" applies controlled concentrations of solutes on human nasal airway mucosa and samples its surface exudations/secretions. Clin Exp Allergy 1990;20:253-9.

10 Cohenford MA, Abraham A, Abraham J, Dain JA. Colometric assay for free and bound L-fucose. Anal Biochem 1989;177:172-7.

11 Greiff L, Wollmer P, Pipkorn U, Persson CGA Absorption of ${ }^{51} \mathrm{Cr}$-EDTA across the human nasal mucosa in the presence of topical histamine. Thorax 1991;146:630-2.

12 Salomonsson $P$, Grönneberg R, Gilljam H, Andersson O Billing B, Enander I, et al. Bronchial exudation of bulk plasma at allergen challenge in allergic asthma. Am Rev Respir Dis 1992;146:1535-42.

13 Erjefält I, Persson CGA. Inflammatory passage of plasma macromolecules into airway wall and lumen. Pulmon Pharmacol 1989;2:93-102.

14 Greiff L, Erjefält I, Wollmer P, Pipkorn U, Persson CGA. Effects of histamine, ethanol, and a detergent on exudation and absorption across guinea pig airway mucosa in vivo. Thorax 1991;46:700-5.

15 Alkner U, Svensson C, Andersson M, Pipkorn U, Persson CGA. Fibrinogen and albumin on the surface of allergen- and histamine-exposed human nasal mucosa. $f$ Allergy Clin Immunol 1991;87:217 (abstract).

16 Persson CGA, Erjefält I, Alkner U, Baumgarten C, Greiff $\mathrm{L}$, Gustafsson B, et al. Plasma exudation as a first line respiratory mucosal defence. Clin Exp Allergy 1991;21: 17-24.

17 Persson CGA, Erjefält I, Gustafsson B, Luts A Subepithelial hydrostatic pressure may regulate plasma exudation across the mucosa. Int Arch Allergy Appl
Immunol 1990;92:148-53.

18 Gustafsson B, Persson CGA. Asymmetrical effects of increases in hydrostatic pressure on macromolecular movement across the airway mucosa. Clin Exp Allergy 1991;21:121-6.

19 Erjefält I. Plasma exudation in tracheobronchial airways: a physiological and pharmacological study in the guinea pig (thesis). Lund: Lund University, 1991.

20 Erjefalt I, Luts A, Persson CGA. The appearance of airway absorption- and exudation-tracers in guinea pig tracheo-bronchial lymphnodes. $f A p p l$ Physiol 1993;74:817-24

21 Bascom R, Kagey-Sobotka A, Proud D. Effect of intranasal capsaicin on symptoms and mediator release. 7 Pharmacol Exp Ther 1991;259:1323-7.

22 Malm L, Petersson G. Tachykinins and nasal secretion. In: Häkansson $\mathrm{R}$, Sundler $\mathrm{F}$, eds. Tachykinin antagonists. Amsterdam: Elsevier, 1985:199-202.

23 Karlsson G, Pipkorn U, Andreasson L. Substance P and human nasal mucociliary activity. Eur $\mathcal{f}$ Clin Pharmacol 1986;30:355-7.

24 Miadonna A, Tedeschi A, Leggieri E, Lorini M, Qualizza $\mathrm{R}$, Froldi $\mathrm{M}$, et al. Activity of substance $\mathrm{P}$ on human skin and nasal airways. Ann Allergy 1988;61:220-3.

25 Gepetti P, Fusco BM, Marabini S, Maggi CA Fanciullacci M, Sicuteri F. Secretion, pain, and sneezing induced by the application of capsaicin to the nasal mucosa in man. Br F Pharmacol 1988;93:509-14.

26 Borson DB, Nadel JA. Regulation of airway secretions: roles of peptides and proteases. In: Mygind N, Pipkor $\mathrm{U}, \mathrm{Dahl} \mathrm{R}$, eds. Rhinitis and asthma: similarities and differences. Copenhagen: Munksgaard, 1990:76-99.

27 Keal EE, Reid L. Pathologic alterations in mucus in asthma within and without the cell. In: Stein M, ed. New directions in asthma. Park Ridge: American College of Chest Physicians, 1975:223-39.

28 Raphael GD, Druce HM, Baraniuk JN, Kaliner MA. The pathophysiology of rhinitis. I. Assessment of the source of protein in methacholine-induced nasal secretions. $A m$ Rev Respir Dis 1988;138:413-20.

29 Jarvis MJ, Hajek P, MAH Russel, West RJ, Feyerabend C. Nasal nicotine solution as an aid to cigarette withdrawal: a pilot clinical trial. $B r \mathcal{F}$ Addict 1987;82:983-8. 